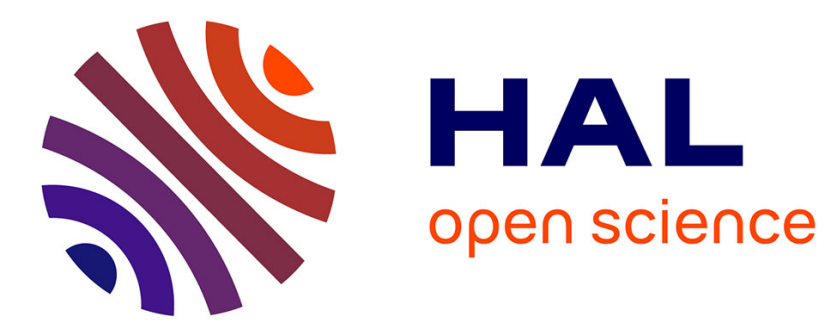

\title{
Antioxidants loss kinetics in polyethylene exposed to model ethanol based biofuels
}

Fatma Djouani, Bhavesh Patel, Emmanuel Richaud, Bruno Fayolle, Jacques

Verdu

\section{- To cite this version:}

Fatma Djouani, Bhavesh Patel, Emmanuel Richaud, Bruno Fayolle, Jacques Verdu. Antioxidants loss kinetics in polyethylene exposed to model ethanol based biofuels. Fuel, 2012, 93, pp.502-509. 10.1016/j.fuel.2011.10.064 . hal-01193052

\section{HAL Id: hal-01193052 \\ https://hal.science/hal-01193052}

Submitted on 14 Feb 2017

HAL is a multi-disciplinary open access archive for the deposit and dissemination of scientific research documents, whether they are published or not. The documents may come from teaching and research institutions in France or abroad, or from public or private research centers.
L'archive ouverte pluridisciplinaire HAL, est destinée au dépôt et à la diffusion de documents scientifiques de niveau recherche, publiés ou non, émanant des établissements d'enseignement et de recherche français ou étrangers, des laboratoires publics ou privés. 


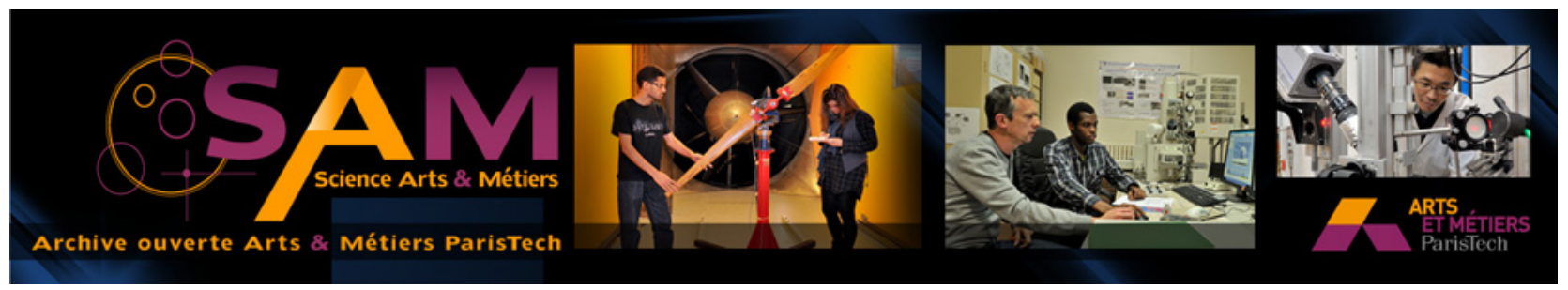

Science Arts \& Métiers (SAM)

is an open access repository that collects the work of Arts et Métiers ParisTech researchers and makes it freely available over the web where possible.

This is an author-deposited version published in: http://sam.ensam.eu

Handle ID: .http://hdl.handle.net/10985/9913

\section{To cite this version :}

Fatma DJOUANI, Bhavesh PATEL, Emmanuel RICHAUD, Bruno FAYOLLE, Jacques VERDU Antioxidants loss kinetics in polyethylene exposed to model ethanol based biofuels - Fuel - Vol. 93, p.502-509. - 2012 


\title{
Antioxidants loss kinetics in polyethylene exposed to model ethanol based biofuels
}

\author{
Fatma Djouani, Bhavesh Patel, Emmanuel Richaud*, Bruno Fayolle, Jacques Verdu \\ Arts et Metiers ParisTech, CNRS, PIMM, 151 bd de l'Hôpital, 75013 Paris, France
}

\begin{abstract}
A B S T R A C T
This work deals with a study of stabilizers loss by extraction in ethanol-cyclohexane mixtures simulating ethanol based biofuels. As theoretically predicted, cyclohexane has an extractive power considerably stronger than ethanol one and its effect predominates, even in fuels containing 50\% ethanol. Antioxidant depletion displays first-order kinetics indicating that loss kinetics are extraction rather than diffusion controlled.
\end{abstract}

Keywords:

Biofuels

Polyethylene

Extraction

Irganox 1010

Irgafos 168

\section{Introduction}

Two recent trends in automotive industry, e.g. the increase of engine temperature and the increasing use of biofuels, lead to reconsider the problem of polymer-fuel interaction for all the polymer materials (polyolefins, polyamides, elastomers, etc.) used in motors and for tanks.

The new biofuel components e.g. essentially ethanol or unsaturated esters, can affect the polymer thermo-oxidative stability by chemical way through co-oxidation process or by physical way through stabilizer extraction. Published works on this topic are very scarce $[1,2]$. It has been observed that polyethylene (PE) displays a poor compatibility with biodiesel fuels. Most of the literature deals with elastomeric sealants swelling when exposed to miscible liquids, especially hydrocarbons $[3,4]$. It has been shown that the degree of swelling is a decreasing function of the crosslink density and of the polymer-fuel interaction parameter, this latter being an increasing function of the difference between polymer and fuel solubility parameters. In the case of HDPE, it has been shown that the tested fuels were absorbed by the polymer but without irreversible modification of the polymer structure [1].

To our knowledge, no paper was published on the eventual stabilizer extraction in PE exposed to biofuels. However, a stabilizer migration from polymer to environment is expected as illustrated by comparable studies in the field of food packaging or pipes industry [5-9]. Short-term effects of biofuels on PE are, no doubt, negligible, but a fast stabilizer extraction could significantly affect

\footnotetext{
* Corresponding author.

E-mail address: emmanuel.richaud@ensam.eu (E. Richaud).
}

the long-term oxidative stability. The coupling of both chemical consumption of stabilizer and physical loss by evaporative process for instance can be simulated by a kinetic model in a case of oxidation [10] but it requires to know the values for kinetic parameters of elementary physical processes such as stabilizer extraction by the liquid (biofuel) medium.

Most of the previous studies devoted to stabilizer physical loss were focused on the diffusion phenomena [8]. In some cases, extraction was observed but not quantified [11] or quantified in the case of thick samples for which stabilizer loss is certainly controlled by diffusion [12] as it will be confirmed in the following. This is the reason why it seemed to us interesting to study antioxidant loss in the presence of biofuels in the case of thin films, which is for us the best way for determining extraction kinetics. It was chosen to study a PE commercial sample stabilized by a common mixture of hindered phenol (Irganox 1010) and phosphite (Irgafos 168). Experiments were also performed with laboratory mode samples containing only Irganox 1010 or Irgafos 168 as model systems. Ethanol based biofuels were simulated by ethanol-cyclohexane mixtures containing $10 \%$ or $50 \%$, ethanol.

\section{Experimental}

\subsection{Materials}

\subsubsection{Commercial polyethylene}

Pellets made from a commercial grade of High Density PolyEthylene (HDPE in the following, density $949 \mathrm{~kg} \mathrm{~m}^{-3}, M_{\mathrm{N}}=18 \mathrm{~kg} \mathrm{~mol}^{-1}$ and $M_{\mathrm{W}}=228 \mathrm{~kg} \mathrm{~mol}^{-1}$ ) were compression molded using a Gibritte laboratory press $\left(30 \mathrm{~s}, 200{ }^{\circ} \mathrm{C}, 24 \mathrm{MPa}\right)$ in order to obtain films of 
$140 \mu \mathrm{m}$ thickness of which melting temperature was c.a. $132^{\circ} \mathrm{C}$ and crystalline ratio value estimated from melting enthalpy was close to $50 \%$ using $290 \mathrm{~J} \mathrm{~g}^{-1}$ as melting enthalpy for an infinite crystal.

\subsubsection{Model polyethylene}

Laboratory made samples were prepared using:

- a stabilizer free PE powder (supplied by Borealis, density $935 \mathrm{~kg} \mathrm{~m}^{-3}$, average molar masse $M_{\mathrm{N}}=8 \mathrm{~kg} \mathrm{~mol}^{-1}$ and $M_{\mathrm{W}}=$ $143 \mathrm{~kg} \mathrm{~mol}^{-1}$ ). The absence of stabilizer was checked by absence of induction period in oxidation kinetics at $180{ }^{\circ} \mathrm{C}$ (see below).

- Irgafos 168 (CAS No. 31570-04-4, supplied by Ciba SC, melting temperature of $185.5^{\circ} \mathrm{C}$ and melting enthalpy close to $73.0 \mathrm{~J} \mathrm{~g}^{-1}$ ) having the following structure:

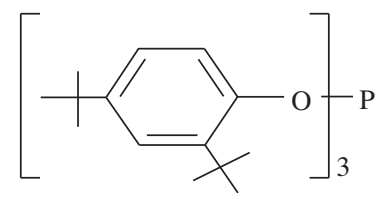

- Irganox 1010 (CAS 98584-37-3, supplied by Ciba SC, melting temperature close to $117.6^{\circ} \mathrm{C}$ a melting enthalpy close to $\left.58.6 \mathrm{~J} \mathrm{~g}^{-1}\right)$.

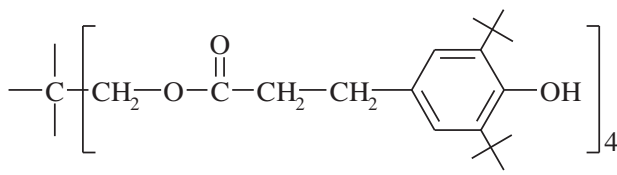

Stabilized PE samples were prepared by pouring a dichloromethane solution of the stabilizer onto PE. The stabilizer concentration and the solution volume are adjusted in order to obtain the desired stabilizer concentration in PE. After evaporation of the solvent at room temperature, about $100 \mu \mathrm{m}$ thick films containing $0.1-0.4 \%$ Irgafos 168 and $0.1-0.5 \%$ Irganox 1010 were prepared by compression molding. They exhibit melting point close to $123^{\circ} \mathrm{C}$, crystallinity ratio estimated from melting enthalpy $x_{\mathrm{C}} \sim 40 \%$ ).

The initial stabilizer concentration in the PE (used for FTIR or UV calibration) was calculated using:

$[\mathrm{Stab}]=\frac{\rho_{\mathrm{PE}}}{M_{\mathrm{Stab}}} \cdot x_{\mathrm{Stab}} \cdot f_{\mathrm{Stab}}$

where $\rho_{\mathrm{PE}}$ is the polymer density $\left(935 \mathrm{~g} \mathrm{l}^{-1}\right), M_{\mathrm{Stab}}$ is the stabilizer molar mass $\left(\mathrm{g} \mathrm{mol}^{-1}\right), x_{\text {Stab }}$ is the global stabilizer weight ratio in the polymer and $f_{\text {Stab }}$ is the stabilizer functionality, i.e. the number of active groups per molecule: 4 for Irganox 1010 and 1 for Irgafos 168.

\subsection{Exposure condition}

A $3 \mathrm{~cm} \times 2 \mathrm{~cm}$ films (thickness being c.a. $140 \mu \mathrm{m}$ ) were immersed in $100 \mathrm{ml}$ model fuel under reflux at c.a. 80 (refluxing temperature of the mixture), 60 and $40{ }^{\circ} \mathrm{C}$ and periodically analyzed. After exposure, sample was quickly removed, air dried at atmospheric pressure and ambient temperature, analyzed and re-immersed. We paid attention to systematically analyse the same "zone" of the sample (i.e. the sample center) to avoid discrepancies due to possible slight fluctuations of stabilizer local concentration or sample thickness). Three model fuels were studied: Ethanol $100 \%$, ethanol-cyclohexane (50/50) and ethanol-cyclohexane (10/90).

\subsection{Analytical methods}

\subsubsection{FTIR spectroscopy}

IR spectra in transmission mode were obtained on a Brucker IFS28 apparatus in standard conditions with averaging 32 scans at a minimal $4 \mathrm{~cm}^{-1}$ resolution. Residual stabilizer concentration in polymer was determined from absorbance values measured at peak maximum by subtracting the baseline value and using Beer Lambert law with molar absorptivity values given in Table 1 .

\subsubsection{Differential scanning calorimetry under oxygen}

Samples (about $5 \mathrm{mg}$ mass) were placed in open aluminum pans. The oxidation induction time (OIT) was determined on a Q10 apparatus (TA Instruments) in the following conditions:

(1) Sample are rapidly heated until $180^{\circ} \mathrm{C}$ and kept $5 \mathrm{~min}$ at this latter temperature to reach thermal equilibrium under nitrogen.

(2) The cell atmosphere was switched to $100 \%$ oxygen (supplied by a $50 \mathrm{ml} \mathrm{min}^{-1}$ flow) and the heat flow was recorded in isothermal condition $\left(180^{\circ} \mathrm{C}\right)$. The end of the induction period is taken at the onset of the exotherm corresponding to the degradation. It has been shown that oxidation induction time (OIT) is almost proportional to the stabilizer concentration for binary mixtures PE + antioxidant [13] as illustrated in Fig. 1a and b, but this is not necessarily true for PE stabilized with synergistic mixtures of antioxidants [14,15].

Let us mention that differential scanning calorimetry under oxygen has many common features with Rancimat. Principle of measurement is to submit virgin or aged hydrocarbon samples (fats, lubricants, oil, polymers) to accelerated ageing whose induction period duration is related to the residual oxidative stability (expressed, in our case, by the residual stabilizer concentration). It is noteworthy that after the end of induction period, all substrate characteristics change suddenly (carbonyl build-up, hydroperoxides concentration, mass loss, elongation at break, residual elongation, etc.) and corresponding induction period values are generally very close. Here the choice of DSC was made for the following reasons:

- According to literature [16,17], Rancimat apparatus is designed for experiments at $100-120^{\circ} \mathrm{C}$ (which is actually a moderate temperature for polymer oxidation). It is particularly well adapted for fats or oil because these ones are very volatile and would quickly evaporate at higher temperatures. For PE + Irgafos 168 or $P E+$ Irganox 1010, the induction period would be respectively on the order of $50 \mathrm{~h}$ and $3000 \mathrm{~h}$ at $120^{\circ} \mathrm{C}$, which is much too long for a rapid stabilizer concentration analysis.

- OIT at $180-200^{\circ} \mathrm{C}$ is not adapted to low molecular mass substrates because of their evaporation. However, for unoxidized PE + stabilizers blends, a linear relationship between OIT value and residual stabilizer concentration permits a fast and fairly precise measure of stabilizer concentration (Fig 1 and $[10,13]$ ).

\subsubsection{Liquid chromatography}

Residual stabilizers and their by-products were removed from polymer films by solvent extraction procedure. Let us mention that several extraction methods (differing by solvent choice and temperature) exist in literature [18-23]. We have chosen chloroform [23] with $16 \mathrm{~h}$ refluxing time but without using an ultrasonic bath. About $0.5 \mathrm{mg}$ of commercial HDPE was reflux-extracted in $50 \mathrm{ml}$ chloroform. The complete extraction was checked by the disappearance of FTIR signals ascribed to stabilizers (see Section 3 part and Table 1) and by the vanishing of OIT at $180^{\circ} \mathrm{C}$. Solution was then filtered and directly analyzed by HPLC using a Waters 
Table 1

Wavenumber, vibration mode and molar absorptivity of characteristics groups of stabilizers main peaks.

\begin{tabular}{|c|c|c|c|c|c|}
\hline & Stabilizer & Wavenumber $\left(\mathrm{cm}^{-1}\right)$ & Compound & $\varepsilon\left(1 \mathrm{~mol}^{-1} \mathrm{~cm}^{-1}\right)$ & $R^{2}$ \\
\hline \multirow{6}{*}{ FTIR } & Irgafos 168 & 772 & $3 *(\mathrm{P}-\mathrm{O}-\mathrm{C})$ & 318 & 0.5513 \\
\hline & Irgafos 168 & 850 & $3 *(\mathrm{P}(\mathrm{III})-\mathrm{O}-\mathrm{Ar})$ & 333 & 0.9385 \\
\hline & Irgafos 168 & 1080 & - & 379 & 0.8055 \\
\hline & Irgafos 168 & 1191 & $3 *(\mathrm{P}-\mathrm{O})$ & 440 & 0.9401 \\
\hline & Irganox 1010 & 1743 & $-\mathrm{O}-\mathrm{C}=\mathrm{O}$ & 322 & 0.8846 \\
\hline & Irganox 1010 & 3650 & $\mathrm{Ar}-\mathrm{OH}$ & 117 & 0.5478 \\
\hline UV & Irganox 1010 & 269 & $\mathrm{Ar}-\mathrm{O}$ & 1355 & 0.6979 \\
\hline
\end{tabular}
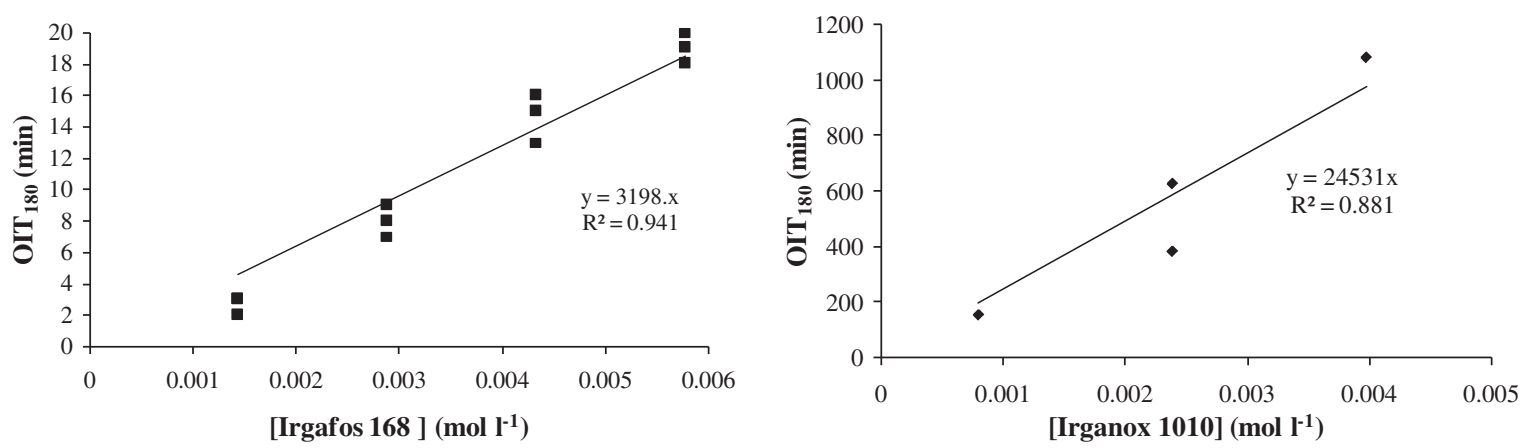

Fig. 1. Initial oxidation induction time values for laboratory made samples stabilized with Irgafos 168 (a) and Irganox 1010 (b).

$717+$ apparatus. Stationary phase was silane grafted C18 thermostated at $35^{\circ} \mathrm{C}$. The mobile phase was acetonitrile (HPLC plus grade, supplied by Carlo Erba) at $1 \mathrm{ml} \mathrm{min}^{-1}$ flow. Detection was performed by Waters 2414 Refractive Index $\left(T_{\text {detector }}=40^{\circ} \mathrm{C}\right)$ and Photo Diode Array Waters 2998 allowing to monitor UV spectra of mobile phase in the $200-400 \mathrm{~nm}$ wavelength range every second. We have focused on the absorption at $270 \mathrm{~nm}$ which permits to monitor aromatic rings of both phosphites [24] and phenols [25].

\section{Results}

\subsection{Calibration of analytical methods}

\subsubsection{FTIR}

FTIR spectra of samples prepared with a single stabilizer are shown in Fig. 2a (Irgafos 168), b and c (Irganox 1010). The absorbances of peaks corresponding to Irgafos 168 and Irganox 1010 increase almost linearly with stabilizers concentration. Their molar absorptivities are listed in Table 1.

For Irgafos 168, many bands could be used to monitor stabilizer loss: $720,855,1080$ and $1191 \mathrm{~cm}^{-1}$. Their advantages or limits for monitoring stabilizer loss are the following:

- A 720 and $1080 \mathrm{~cm}^{-1}$ overlap with bands of PE matrix that induces scatter in quantitative determinations. Furthermore their assignment is not trivial especially for $1080 \mathrm{~cm}^{-1}$ peak.

- Peak at 1191 ( $\mathrm{P}-\mathrm{O}$ in phosphite) is clearly identified. Even if it slightly overlaps with $1211 \mathrm{~cm}^{-1}$ ( $\mathrm{P}-\mathrm{O}$ in phosphate [26]), it was preferred to the peak at $850 \mathrm{~cm}^{-1}$ because it is less scattered.

For phenols, stabilizer loss can be monitored by 1740 and $3650 \mathrm{~cm}^{-1}$ (see Fig. 2b and c). Ester absorption at c.a. $1740 \mathrm{~cm}^{-1}$ has two advantages: first, it has a higher molar absorptivity than $3650 \mathrm{~cm}^{-1}$, and second, it does not overlap with PE matrix absorption meanwhile $\mathrm{OH}$ signal does (which is certainly the reason why scatter is higher for ester than for phenols (Table 1)).
UV analysis (not shown here) were also performed. UV spectra displayed a band at $269 \mathrm{~nm}$ for PE + Irganox 1010 but quantitative analysis was undoubtedly less reliable from UV data than from OIT or FTIR data so that it will not be used in this study. Beer-Lambert plots for peaks at $1191 \mathrm{~cm}^{-1}$ (Irgafos 168) and $1743 \mathrm{~cm}^{-1}$ (Irganox 1010) will be used in the following to monitor the stabilizer loss kinetics during exposure.

The Irgafos 168 bands are clearly distinguishable in the commercial sample. In contrast, Irganox 1010 bands are too weak to allow quantitative measurements, despite the fact that the presence of the stabilizer is confirmed by HPLC (see below).

\subsubsection{HPLC analysis of commercial PE}

Overlapping of stabilizer chromatograms obtained in separate runs is shown in Fig. 3a. Irganox 1010 displays a peak at $8.2 \mathrm{~min}$ with a shoulder at 9 min and several small peaks between 2 and 7 min.

Irgafos 168 displays a predominating peak at $28 \mathrm{~min}$ and a shoulder at 31-32 min. In both cases, secondary peaks indicate the existence of isomers and/or impurities, which is not surprising for commercial grades.

The chromatogram of removed materials (stabilizers together with their impurities and process induced by-products) by chloroform extraction from commercial PE reveals the presence of both stabilizers (Fig. 3b). The additional peak observed at 15 min corresponds to the phosphate generated from Irgafos 168 oxidation (as shown in [24] by reacting Irgafos 168 with tert-butyl hydroperoxide). These results confirm thus a limited oxidation during sample processing.

In conclusion, the commercial PE is suspected to contain both Irgafos 168 and Irganox 1010 which is not surprising since this is a very common stabilizer blend characterized by a strong synergistic effect $[14,15]$.

\subsection{Physical loss kinetics}

Commercial PE samples of $140 \mu \mathrm{m}$ thickness were exposed in the three model fuels containing respectively $100 \%$ (ethanol), $50 \%$ (E50) and $10 \%$ (E10) ethanol at reflux $\left(80^{\circ} \mathrm{C}\right)$. The decrease of 

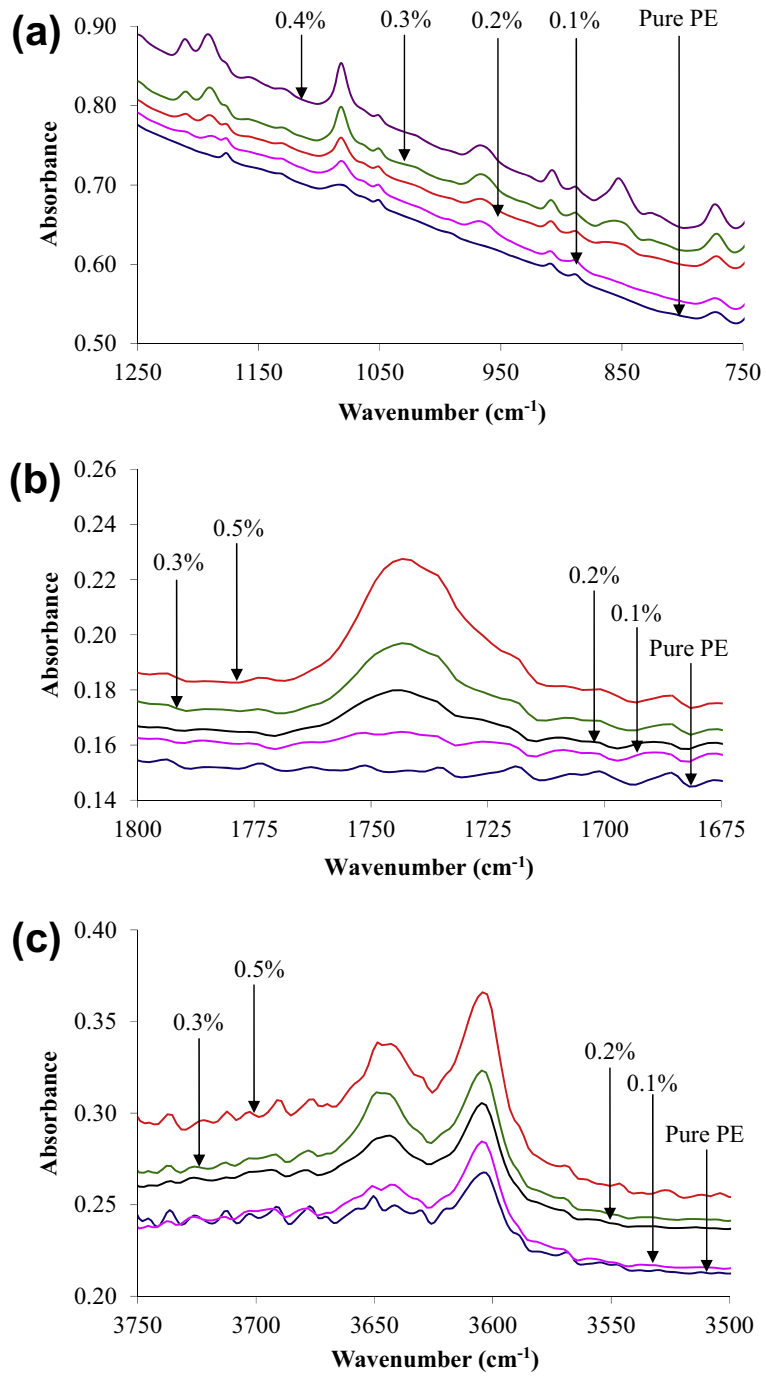

Fig. 2. FTIR spectra for films stabilized with various amounts of Irgafos 168 (a) Irganox 1010 (b)

residual stabilizer concentration was monitored by OIT measurement. The kinetic curves of OIT change are shown in Fig. 4. These results call for the following comments:

(1) Extraction is considerably slower in pure ethanol than in cyclohexane containing fuels. Concerning these latter, there is practically no difference between E10 and E50 and, presumably pure cyclohexane. It has been already shown that the extractive power of liquids decreases when the polarity difference between the polymer and the liquid increases [27], but there was, to our knowledge, no proposal for a quantitative relationship between the extraction rate and the polymer, the additive and the liquid characteristics.

(2) It has been tried to fit the OIT decay curves by a simple firstorder model (Eqs. (2) and (3)). The agreement with experimental data is satisfying provided an asymptotic (residual) OIT value (denoted by $\mathrm{OIT}_{\infty}$ ) is taken into account:

$\frac{\mathrm{dOIT}}{d t}=-\beta\left(\mathrm{OIT}-\mathrm{OIT}_{\infty}\right)$

e.g. $\mathrm{OIT}=\mathrm{OIT}_{\infty}+\left(\mathrm{OIT}_{0}-\mathrm{OIT}_{\infty}\right) \cdot \exp (-\beta \cdot t)$

$\mathrm{OIT}_{0}$ being the initial OIT value before exposure and $\beta$ a pseudo first-order rate constant characterizing the stabilizer loss.
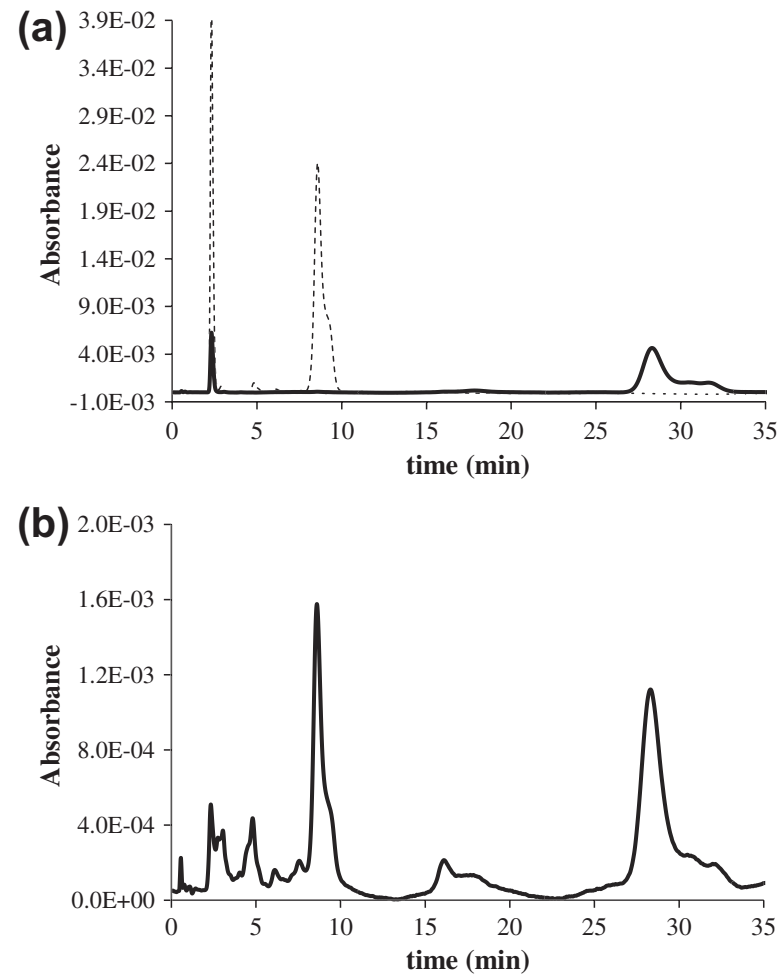

Fig. 3. HPLC chromatogram for (a) standard solution of Irganox 1010 (dashed line), Irgafos 168 (full line) and (b) extracted solution from commercial PE sample.

Asymptotic values of induction time $\mathrm{OIT}_{\infty}$ and pseudo first-order constant $\beta$ values are listed in Table 2. Here, the existence of a permanent residual stabilizer concentration can be attributed to the limited efficiency of the chosen extraction method. Since, always, $\mathrm{OIT}_{\infty} \ll \mathrm{OIT}_{0}$, the existence of this residual concentration can be neglected in a coarse grain kinetic study and it can be considered that the OIT decay is a simple first-order process.

For laboratory samples containing a single stabilizer, the stabilizer depletion during exposure in pure ethanol at 40,60 and $80^{\circ} \mathrm{C}$ has been monitored by IR using the ester peak at $1743 \mathrm{~cm}^{-1}$ for Irganox 1010 (Fig. 5a) and at $1191 \mathrm{~cm}^{-1}$ for Irgafos 168 (Fig. 5b). Assuming first-order kinetics, it has been tried to determine the best value of the rate constant $\beta$. Corresponding values are reported in Table 3 together with correlation coefficient $R^{2}$. It appears that the kinetics are effectively a first-order process in the case of Irgafos 168. This is less obvious for Irganox 1010 for which the correlation coefficients are very low at 60 and $80^{\circ} \mathrm{C}$. One can observe that $\beta$ is actually independent of the initial stabilizer concentration as expected for a first-order kinetic (see Fig. 6).

It seemed to us interesting to show Arrhenius plots of all the available $\beta$ parameters obtained irrespective of the initial stabilizer concentration and the analysis technique (FTIR or OIT). The results are shown in Fig. 7. Even if they have to be considered with caution, they seem to indicate that:

(1) As expected, the rate of Irgafos 168 loss is the same in commercial as in laboratory made samples. Unfortunately this was impossible to check in the case of Irganox 1010 owing to the weakness of its IR bands in commercial PE sample.

(2) The apparent activation energy was lower for Irgafos 168 $\left(90 \pm 10 \mathrm{~kJ} \mathrm{~mol}^{-1}\right)$ than for Irganox $1010\left(110 \pm 10 \mathrm{~kJ} \mathrm{~mol}^{-1}\right)$.

\section{Discussion}

Cyclohexane is especially efficient in extracting stabilizers from PE since its solubility parameter $\left(\sim 16.7 \mathrm{MPa}^{1 / 2}\right)$ is very close to the 

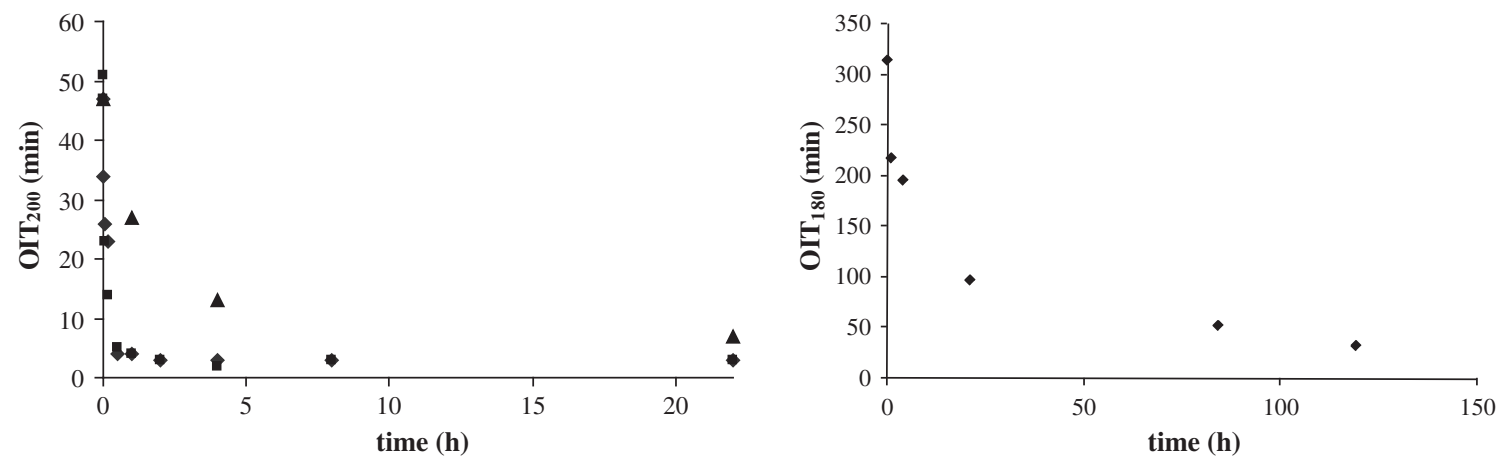

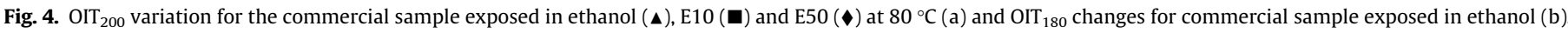

Table 2

Apparent depletion rate and asymptotic value for residual oxidation induction time at $200{ }^{\circ} \mathrm{C}$ for commercial PE.

\begin{tabular}{llll}
\hline & EtOH & $50 \% \mathrm{EtOH}$ & $10 \% \mathrm{EtOH}$ \\
\hline $\mathrm{OIT}_{\infty}(\min )$ & 7 & 3 & 2 \\
$\beta\left(\mathrm{h}^{-1}\right)$ & 0.449 & 4.459 & 4.713
\end{tabular}

polymer one (15.8-17.1 $\mathrm{MPa}^{1 / 2}$ ) [27]. It is thus able to swell PE and to favor the stabilizer transport through the polymer matrix. Ethanol, of which the solubility parameter $\left(26.3 \mathrm{MPa}^{1 / 2}\right)$ is far from PE one, does not swell PE and displays thus a considerably lower extractive power.

Our results reveal an apparent discrepancy. According to the data of Fig. 4 and Table 3, Irgafos 168 is expected to be predominantly lost in the first hours of exposure in the commercial PE sample containing a binary stabilizer mixture. According to the OIT values obtained with unextracted single stabilizer systems (Fig. 1a for Irgafos 168, Fig. 1b for Irganox 1010), and supposing a linear dependence of OIT with stabilizer concentrations, the loss of Irgafos 168 in the first hour of exposure in ethanol at $80^{\circ} \mathrm{C}$

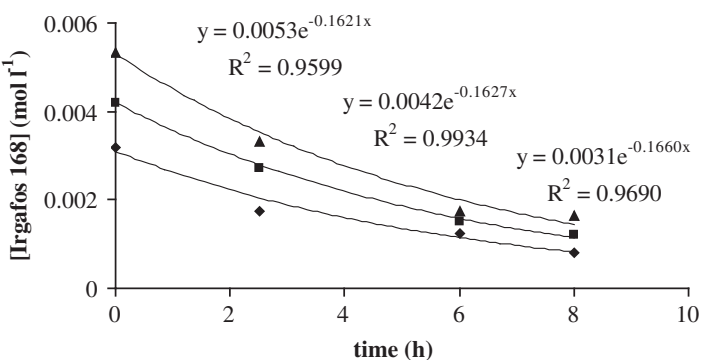

Fig. 6. Exposure of laboratory made samples containing $0.2 \%(\bullet), 0.3 \%(\boldsymbol{\square})$ and $0.4 \%$ (ム) Irgafos 168 at $60^{\circ} \mathrm{C}$ in pure ethanol.

(Fig. 3) would be expected to have a little influence on OIT provided Irganox 1010 and Irgafos 168 contributions are additive. This is contradicted by experimental results: OIT decreases by more than $40 \%$ of its initial value after $1 \mathrm{~h}$ of exposure. It can be also noticed that the pseudo-first order rate constant $\beta$ for OIT decrease is considerably higher than the first-order rate constants $\beta$ for single stabilizers physical loss. The explanation is obvious: Irgafos 168
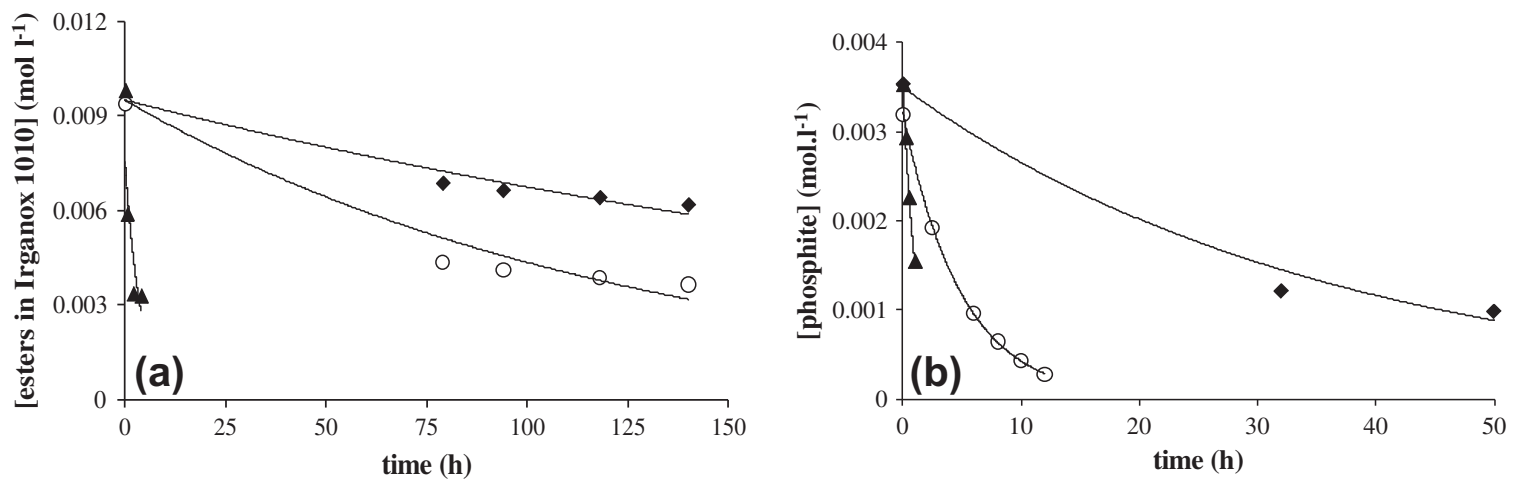

Fig. 5. Exposure of laboratory made samples containing Irganox 1010 (a) and Irgafos 168 (b) stabilizer loss at $40{ }^{\circ} \mathrm{C}(\diamond), 60{ }^{\circ} \mathrm{C}(\mathrm{O})$ and $80{ }^{\circ} \mathrm{C}(\Delta)$ in pure ethanol.

Table 3

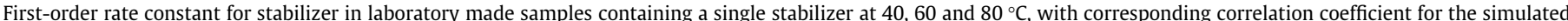
first-order curves and estimation of time for crossing the interface, minimum and maximum values of the ratio of characteristic times (see text).

\begin{tabular}{|c|c|c|c|c|c|c|c|c|c|}
\hline & $T\left({ }^{\circ} \mathrm{C}\right)$ & $\beta\left(\mathrm{h}^{-1}\right)$ & $\tau_{I}(\mathrm{~s})$ & $R^{2}$ & $D_{\max }\left(\mathrm{m}^{2} \mathrm{~s}^{-1}\right)$ & $D_{\min }\left(\mathrm{m}^{2} \mathrm{~s}^{-1}\right)$ & $e(\mathrm{~m})$ & $h_{\max }$ & $h_{\min }$ \\
\hline \multirow{3}{*}{ Irganox 1010} & 80 & $2.5 \mathrm{E}-01$ & $1.4 \mathrm{E}+04$ & 0.7365 & $7.4 \mathrm{E}-13$ & $5.9 \mathrm{E}-14$ & $1.0 \mathrm{E}-04$ & $1.2 \mathrm{E}+01$ & $9.4 \mathrm{E}-01$ \\
\hline & 60 & $1.3 \mathrm{E}-02$ & $2.7 \mathrm{E}+05$ & 0.8197 & $6.9 \mathrm{E}-14$ & $9.9 \mathrm{E}-15$ & $1.0 \mathrm{E}-04$ & $3.8 \mathrm{E}+00$ & $5.4 \mathrm{E}-01$ \\
\hline & 40 & $3.3 \mathrm{E}-\mathrm{O} 3$ & $1.1 \mathrm{E}+06$ & 0.9448 & $5.8 \mathrm{E}-15$ & $1.3 \mathrm{E}-15$ & $1.0 \mathrm{E}-04$ & $6.8 \mathrm{E}+00$ & $1.6 \mathrm{E}+00$ \\
\hline \multirow{3}{*}{ Irgafos 168} & 80 & $8.4 \mathrm{E}-01$ & $4.3 E+03$ & 0.9998 & $1.2 \mathrm{E}-11$ & $9.7 \mathrm{E}-13$ & $1.0 \mathrm{E}-04$ & $2.4 \mathrm{E}+00$ & $1.9 \mathrm{E}-01$ \\
\hline & 60 & $2.0 \mathrm{E}-01$ & $1.8 \mathrm{E}+04$ & 0.9534 & $2.1 \mathrm{E}-12$ & $1.6 \mathrm{E}-13$ & $1.0 \mathrm{E}-04$ & $3.5 \mathrm{E}+00$ & $2.7 \mathrm{E}-01$ \\
\hline & 40 & $2.7 \mathrm{E}-02$ & $1.3 \mathrm{E}+05$ & 0.9963 & $2.8 \mathrm{E}-13$ & $2.2 \mathrm{E}-14$ & $1.0 \mathrm{E}-04$ & $3.5 \mathrm{E}+00$ & $2.7 \mathrm{E}-01$ \\
\hline
\end{tabular}




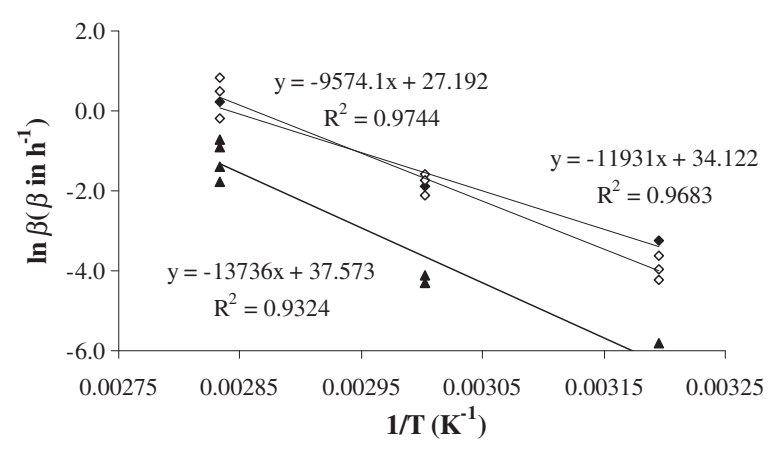

Fig. 7. Arrhenius plot for FTIR data for PE + Irgafos 168 film surface, PE + Irganox1010 and commercial HDPE.

depletion leads to the disappearance of a synergistic interaction with Irganox 1010, which has a greatest influence on residual oxidative stability. The existence of such synergistic effect makes the dependence of OIT with stabilizer concentration strongly nonlinear $[14,15]$. From the practical point of view, OIT data are relatively easy to use for quantitative studies of stabilizer consumption in single stabilizer systems, but they are to be considered with caution in the cases of multiple stabilizers systems. At long exposure times, the existence of a residual OIT value for commercial PE sample indicates that stabilizer seems not to be completely extracted contrarily to the case of laboratory made PE samples (Fig. 5). A possible explanation is the difference between commercial PE (HDPE) and the one used for preparing laboratory made samples (MDPE). The differences in microstructure and in thickness are expected to modify respectively the values for diffusion coefficient and time for migrating from bulk to surface and hence the kinetic control by diffusion (see later).

Whatever the physical meaning of the reported rate constant values, they clearly put in evidence the fact that extraction is noticeably faster for Irgafos 168 than for Irganox 1010. In the case of evaporation, this would be easily explainable by the well-known effect of molecular weight ( $646 \mathrm{~g} \mathrm{~mol}^{-1}$ for Irgafos 168 against $1178 \mathrm{~g} \mathrm{~mol}^{-1}$ for Irganox 1010) on volatility. It could be reasonably supposed that additive extractibility is first linked to its solubility in the liquid and that solubility displays only a second-order dependence with molar mass (in the molar mass domain under consideration). The fact that stabilizer extractability is molar mass dependent shows that structure-extractability relationships remain an open research domain.

It remains to try to justify the apparent first-order character of extraction kinetics in the case of Irgafos 168 and the fact that it is less obvious in the case of Irganox 1010. It can be recalled that this phenomenon results from the sequence of two physical processes: first the diffusion of additive molecules from their initial location to the surface, second the interface crossing and the passage of the molecule from polymer into the media. This process is called evaporation in gaseous media and extraction in liquid media. Two extreme cases can be imagined:

(1) "Interface crossing" is considerably faster than diffusion, then, diffusion controls the whole stabilizer loss kinetics.

(2) Diffusion is fast enough to redistribute homogeneously the stabilizer in the whole sample thickness at every time. Loss kinetics is hence controlled by "interface crossing". In the initial steps of a fickian diffusion process, the stabilizer concentration is expected to decrease proportionally to the square root of time.

The competition between both processes was first modeled by Crank [28]. The criterion proposed by this author was then used by Calvert and Billingham [12] in the case of polymer-stabilizer systems. In such systems, it can be assumed that:
- Stabilizer concentrations are low enough (generally lower than $0.5 \%$ [14]) to neglect the plasticizing effects so that diffusion is really Fickian and the diffusion coefficient is concentration independent [29].

- Extraction could obey the same type of kinetic law as evaporation. This latter is usually derived from two hypotheses:

(1) The first hypothesis states that the loss rate of additive in a saturated sample $\left(r_{\text {Sat }}\right)$ is equal to the loss rate of pure additive $\left(r_{\text {pure }}\right)$ in liquid state:

$\left(\frac{d n_{\mathrm{A}}}{d t}\right)_{\mathrm{Sat}}=-r_{\mathrm{Sat}}=-r_{\text {pure }}$

$r_{\text {Sat }}$ and $r_{\text {pure }}$ being in mol $\mathrm{m}^{-2} \mathrm{~s}^{-1}$, and $n_{\mathrm{A}}$ being the number of molecule A lost per area unit.

(2) The second hypothesis states that, in a non saturated sample, for a given additive concentration $[A]$, the lost rate is proportional to $[\mathrm{A}]$ so that:

$\frac{\frac{d n_{\mathrm{A}}}{d t}}{\left(\frac{d n_{\mathrm{A}}}{d t}\right)_{\mathrm{Sat}}}=\frac{[A]}{[A]_{\mathrm{Sat}}}$

so that:

$\frac{d n_{\mathrm{A}}}{d t}=\frac{r_{\mathrm{Sat}}}{[A]_{\mathrm{Sat}}} \cdot[A]$

If interface crossing controls the whole kinetics, this means that diffusion is fast enough to redistribute homogeneously the stabilizer in the whole sample thickness (denoted by $L$ ) at every time. The decrease of additive concentration obeys thus a first-order law:

$\frac{d[A]}{d t}=-\frac{1}{L} \cdot \frac{d n_{\mathrm{A}}}{d t}=-\beta[A]$

in which : $\beta=\frac{1}{L} \cdot \frac{r_{\mathrm{Sat}}}{[A]_{\mathrm{Sat}}}$

$\beta$ being a first-order rate constant characteristic of the sample thickness under consideration.

Since loss kinetics obeys effectively first-order law in the case of Irgafos 168, the analogy between extraction and evaporation is confirmed. Then, the lack of correlation between experimental data and first-order kinetic curves in the case of Irganox 1010 can be tentatively explained by the fact that this system is on the other side of the boundary between extraction controlled and diffusion controlled kinetic regimes for the sample thickness under consideration $(\sim 140 \mu \mathrm{m})$.

A simple reasoning aimed to determine the rate controlling step for physical loss can be made from:

(1) a characteristic time for interface crossing $\tau_{I}$ :

$\tau_{I}=\beta^{-1}=L \cdot \frac{[A]_{\text {Sat }}}{r_{\text {Sat }}}$

(2) a characteristic time of diffusion $\tau_{D}$ : $\tau_{D}=L^{2} / D$

$D$ being the diffusion coefficient of stabilizer through the polymer.

(3) an adimensional number $h$ analogous to a Deborah number by the ratio of characteristic times:

$h=\frac{\tau_{D}}{\tau_{I}}=\frac{L \cdot r_{\mathrm{Sat}}}{D_{\mathrm{A}} \cdot[A]_{\mathrm{Sat}}}$

- if $h \gg 1\left(\tau_{I} \ll \tau_{D}\right)$, diffusion is the rate controlling processing, the profile of additive concentration into the sample thickness will display a strong gradient in the superficial layer, the concentration being almost zero at the surface. 
Table 4

Diffusion coefficient for Irganox 1010.

\begin{tabular}{llllll}
\hline & $\begin{array}{l}T \\
\left({ }^{\circ} \mathrm{C}\right)\end{array}$ & $\begin{array}{l}\text { Moisan } \\
{[30]}\end{array}$ & $\begin{array}{l}\text { Begley et al. } \\
{[8]}\end{array}$ & $\begin{array}{l}\text { Limm et al. } \\
{[31]}\end{array}$ & $\begin{array}{l}\text { Brandsch et al. } \\
{[32]}\end{array}$ \\
\hline \multirow{2}{*}{ LDPE } & 40 & $4.84 \mathrm{E}-15$ & $3.10 \mathrm{E}-15$ & $5.80 \mathrm{E}-15$ & $1.34 \mathrm{E}-15$ \\
& 60 & $6.93 \mathrm{E}-14$ & $2.30 \mathrm{E}-14$ & $5.83 \mathrm{E}-14$ & $9.91 \mathrm{E}-15$ \\
& 80 & $7.36 \mathrm{E}-13$ & $1.36 \mathrm{E}-13$ & $4.52 \mathrm{E}-13$ & $5.86 \mathrm{E}-14$ \\
HDPE & 40 & $4.84 \mathrm{E}-15$ & $4.05 \mathrm{E}-16$ & $1.08 \mathrm{E}-18$ & $6.66 \mathrm{E}-17$ \\
& 60 & $6.93 \mathrm{E}-14$ & $4.06 \mathrm{E}-15$ & $3.80 \mathrm{E}-17$ & $4.94 \mathrm{E}-16$ \\
& 80 & $7.36 \mathrm{E}-13$ & $3.14 \mathrm{E}-14$ & $8.95 \mathrm{E}-16$ & $2.92 \mathrm{E}-15$ \\
\hline
\end{tabular}

Table 5

Diffusion coefficient for Irgafos 168.

\begin{tabular}{llllll}
\hline & $\begin{array}{l}T \\
\left({ }^{\circ} \mathrm{C}\right)\end{array}$ & $\begin{array}{l}\text { Begley et al. } \\
{[8] \mathrm{min}}\end{array}$ & $\begin{array}{l}\text { Begley et al. } \\
{[8] \mathrm{max}}\end{array}$ & $\begin{array}{l}\text { Limm et al. } \\
{[31]}\end{array}$ & $\begin{array}{l}\text { Brandsch } \\
\text { et al. [32] }\end{array}$ \\
\hline \multirow{2}{*}{ LDPE } & 40 & $2.21 \mathrm{E}-14$ & $5.73 \mathrm{E}-14$ & $4.43 \mathrm{E}-14$ & $2.82 \mathrm{E}-13$ \\
& 60 & $1.64 \mathrm{E}-13$ & $4.25 \mathrm{E}-13$ & $2.93 \mathrm{E}-13$ & $2.09 \mathrm{E}-12$ \\
& 80 & $9.71 \mathrm{E}-13$ & $2.51 \mathrm{E}-12$ & $1.57 \mathrm{E}-12$ & $1.24 \mathrm{E}-11$ \\
HDPE & 40 & $3.91 \mathrm{E}-16$ & $8.98 \mathrm{E}-14$ & $3.47 \mathrm{E}-17$ & $1.41 \mathrm{E}-14$ \\
& 60 & $3.93 \mathrm{E}-15$ & $6.66 \mathrm{E}-13$ & $6.43 \mathrm{E}-16$ & $1.04 \mathrm{E}-13$ \\
& 80 & $3.04 \mathrm{E}-14$ & $3.94 \mathrm{E}-12$ & $8.54 \mathrm{E}-15$ & $6.16 \mathrm{E}-13$ \\
\hline
\end{tabular}

- if $h \ll 1\left(\tau_{I} \gg \tau_{D}\right)$, the interface crossing is slow and, then diffusion is fast enough to redistribute homogenously the additive into the whole thickness, the concentration profile is flat.

A more or less wide transition exists around $h=1$. It can be also seen that the boundary between both regimes depends on the sample thickness. Using Crank's equation, Calvert and Billingham [12] reached the same criterion as the above one and determined its value for two sample geometries (e.g. foils or cylindrical fibers). In the case of foils, they have shown that the process is extraction controlled for $h<0.6$ and diffusion controlled for $h>10$.

It seemed interesting to us to try to determine the ratio of characteristic times using experimental data reported by Moisan [30], Limm and Hollifield [31] for Irganox 1010, and by Begley et al. for Irgafos 168 [8], together with values estimated from models [32] (Table 4 and 5). According to its crystallinity ratio ( $50 \%)$, the polyethylene under investigation is closer to LDPE than to HDPE. In the following only LDPE characteristics will be used in comparisons.

The extreme values of the characteristic times ratio $h$ are given in Table 2. It appears interesting to interpret these results using the criteria of Calvert and Billingham [12]. According to the maximum values of $h$, all PE + stabilizer systems would be in the transition regime except Irganox 1010 at $80^{\circ} \mathrm{C}$ for which loss kinetics would be diffusion controlled. It is interesting to note that this latter case displays logically the major deviation from first-order e.g. extraction controlled kinetics (Table 3). However, maximum $h$ values seem to disagree with experimental data for Irgafos 168 . As a matter of fact, loss kinetics obey clearly first-order law in this latter case, what indicates that the system is in extraction controlled regime. Minimum values of $h$ tend to give a more consistent view of the whole results: PE + Irgafos 168 systems would be clearly in extraction controlled regime whereas PE + Irganox 1010 ones would be in the transition regime, not very far from its lower boundary, which explains the observed more or less slight deviations from first-order kinetics.

\section{Conclusion}

Polyethylene samples stabilized by Irganox 1010 or by Irgafos 168 or by a synergistic mixture of both have been exposed at 40 , 60 and $80{ }^{\circ} \mathrm{C}$, in cyclohexane-ethanol mixtures with $10 \%, 50 \%$ or
$100 \%$ ethanol, simulating biofuels. The antioxidant loss has been studied by IR and HPLC and, in the case of the sample stabilized by the antioxidants mixture, by induction time (at $180^{\circ} \mathrm{C}$ ) measurements. It was previously found that in samples stabilized by a single stabilizer, induction time is almost proportional to antioxidant concentration. In the sample stabilized by a stabilizer mixture, in contrast, the OIT decay is noticeably faster than expected from linear concentration dependence owing to the strong contribution of synergy. It appears that extraction is considerably faster in the presence of cyclohexane, even at its lowest concentration (10\%) than in ethanol. These results suggest that ethanol based biofuels are not more aggressive towards PE parts than classical hydrocarbon fuels. Antioxidant loss kinetics has been studied in pure ethanol and compared with theoretical first-order kinetics. There is a high degree of correlation in the case of Irgafos 168 , and a significant deviation in the case of Irganox 1010. For the interpretation of these results it is first assumed that extraction obeys the same kinetic laws as evaporation. It is shown that these phenomena must be first-order processes. The results can be then explained using a simplified version of Crank's theory [28] and a criterion proposed by Calvert and Billingham about 30 years ago [12] This criterion is based on the ratio $h$ of diffusion and extraction characteristic times. According to both experimental and literature data on diffusion coefficients, it appears that Irgafos 168 systems would be in extraction controlled regime whatever the temperature, whereas Irganox 1010 systems would be in the transition domain between extraction controlled and diffusion controlled kinetic regimes. From a theoretical point of view, it was already known that the choice of a stabilizer depends on its chemical efficiency in the considered temperature range [14,24], and that, in a given stabilizer family, the performances of two stabilizers (for example two phenols differing by their para-substituent nature) could be described by functions of diffusivity and solubility in polymer matrix [33]. This work suggests that, for more complex applications (here in presence of fuels), their relative compatibility with polyethylene, hydrocarbon fuel and ethanol has also to be taken into account

\section{Acknowledgements}

This work has been accomplished in the frame of the "contract "BioCarbMat" and sponsored by the competitivity pole MOV'EO which is gratefully acknowledged.

\section{References}

[1] Maru MM, Lucchese MM, Legnani C, Quirino WG, Balbo A, Bulhões Aranha I, et al. Biodiesel compatibility with carbon steel and HDPE parts. Fuel Process Technol 2009;90(9):1175-82.

[2] Haseeb ASMA, Fazal MA, Jahirul MI, Masjuki HH. Compatibility of automotive materials in biodiesel: a review. Fuel 2011;90(3):922-31.

[3] Trakarnpruk W, Porntangjitlikit S. Palm oil biodiesel synthesized with potassium loaded calcined hydrotalcite and effect of biodiesel blend on elastomer properties. Renew Energy 2008;33(7):1558-63.

[4] Flitney B. Which elastomer seal materials are suitable for use in biofuels? Seal Technol 2007;2007(9):8-11.

[5] Lundbäck M, Hedenqvist MS, Mattozzi A, Gedde UW. Migration of phenolic antioxidants from linear and branched polyethylene. Polym Degrad Stab 2006;91(7):1571-80

[6] Lundbäck M, Strandberg C, Albertsson AC, Hedenqvist MS, Gedde UW. Loss of stability by migration and chemical reaction of Santonox ${ }^{\circledR} \mathrm{R}$ in branched polyethylene under anaerobic and aerobic conditions. Polym Degrad Stab 2006:91(5):1071-8.

[7] Lickly TD, Belle CD, Kehr KM. The migration of Irganox 1010 from high-density polyethylene and polypropylene into a series of potential fatty-food simulants. Food Addit Contam 1990;7(6):805-14.

[8] Begley T, Castle L, Feigenbaum A, Franz R, Hinrichs K, Lickly T, et al. Evaluation of migration models that might be used in support of regulations for foodcontact plastics. Food Addit Contam 2005;22(1):73-90.

[9] Helmroth E, Rijk R, Dekker M, Jongen W. Predictive modeling of migration from packaging materials into food products for regulatory purposes. Trends Food Sci Technol 2002;13(3):102-9. 
[10] Richaud E, Monchy-Leroy C, Colin X, Audouin L, Verdu J. Kinetic modelling of stabilization coupled with stabilizer loss by evaporation. Case of dithioester stabilized polyethylene. Polym Degrad Stab 2009;94(11):2004-14.

[11] Dörner G, Lang RW. Influence of various stabilizer systems on the ageing behavior of PE-MD-II. Ageing of pipe specimens in air and water at elevated temperatures. Polym Degrad Stab 1998;62(3):431-40.

[12] Calvert PD, Bellingham NC. Loss of additives from polymers: a theoretical model. J App Polym Sci 1979;24(2):357-70.

[13] Richaud E, Colin X, Monchy-Leroy C, Audouin L, Verdu J. Polyethylene stabilization against thermal oxidation by a trimethylquinoleine oligomer. Poly Degrad Stab 2009;94(3):410-20.

[14] Schwarzenbach K, Gilg B, Muller D, Knobloch G, Pauquet JR, Rota-Graziosi P, et al. Antioxidants. In: Zweifel $\mathrm{H}$, editor. Plastics additives handbook, Fth ed. Cincinatti: Hanser Gardner Publications, Inc.; 2001.

[15] Verdu J, Rychly J, Audouin L. Synergism between polymer antioxidantskinetic modeling. Polym Degrad Stab 2003;79(3):503-9.

[16] Velasco J, Andersen ML, Skibsted LH. Evaluation of oxidative stability of vegetable oils by monitoring the tendency to radical formation. A comparison of electron spin resonance spectroscopy with the Rancimat method and differential scanning calorimetry. Food Chem 2004;85(4):623-32.

[17] Velasco J, Dobarganes C, Holgado F, Márquez-Ruiz G. A follow-up oxidation study in dried microencapsulate oils under the accelerated conditions of the Rancimat test. Food Res Int 2009;42(1):56-62.

[18] Carpentieri I, Brunella V, Bracco P, Paganini MC, Brach del Prover EM, Luda MP, et al. Post-irradiation oxidation of different polyethylenes. Polym Degrad Stab 2011;96(4):624-9.

[19] Tidjani A. Comparison of formation of oxidation products during photooxidation of linear low density polyethylene under different natural and accelerated weathering conditions. Polym Degrad Stab 2000;68(3):465-9.

[20] Celina M, George GA. Characterisation and degradation studies of peroxide and silane crosslinked polyethylene. Polym Degrad Stab 1995;48(2):297-312.

[21] Ken Busfield W, Tuba P. Photo-oxidative degradation of mechanically stressed polyolefins. Polym Degrad Stab 1996;51(2):185-96.
[22] Khelidj N, Colin X, Audouin L, Verdu J, Monchy-Leroy C, Prunier V. Oxidation of polyethylene under irradiation at low temperature and low dose rate. Part II. Low temperature thermal oxidation. Polym Degrad Stab 2006;91(7):1598-605.

[23] Haider N, Karlsson S. A rapid ultrasonic extraction technique to identify and quantify additives in polyethylene). Analyst 1999;124(5):797-800.

[24] Djouani F, Richaud E, Fayolle B, Verdu J. Modelling of thermal oxidation of phosphite stabilized polyethylene. Polym Degrad Stab 2011;96(7):1349-60.

[25] Navarro R, Audouin L, Verde J. Reactions of antioxidants with molecular oxygen. Part II. Isooctyl-3-(3,5-di-tert-butyl-4-hydroxyphenyl)propionate in silicone matrix. Polym Degrad Stab 2011;96(5):965-73.

[26] Pénzes G, Domján A, Tátraaljai D, Staniek P, Földes E, Pukánszky B. High temperature reactions of an aryl-alkyl phosphine, an exceptionally efficient melt stabiliser for polyethylene. Polym Degrad Stab 2010;95(9):1627-35.

[27] Van Krevelen DW. Properties of polymers, their correlation with chemical structure, their numerical estimations and prediction from additive group contributions, 3rd ed. Amsterdam, Lausanne, New York, Oxford, Shannon, Tokyo: Elsevier; 1990.

[28] Crank J. The mathematics of diffusion. and ed. Oxford: Oxford science publications; 1979.

[29] Földes E. Transport of small molecules in polyolefins. II. Diffusion and solubility of irganox 1076 in ethylene polymers. J App Poly Sci 1993;48(11):1905-13.

[30] Moisan JY. Diffusion des additifs du polyethylene-I: influence de la nature du diffusant. Eur Polym J 1980;16(10):979-87.

[31] Sim W, Hollifield HC. Modelling of additive diffusion in polyolefins. Food Addict Contam A 1996;13(8):949-67.

[32] Brandsch J, Merced P, Piringer O. Modeling of additive diffusion coefficients in polyolefins. In: Rich SJ, editor. Food packaging testing methods and applications, vol. 753. Washington DC: ACS Symposium Series; 2000. p. :2736.

[33] Malík J, Tun DQ, Špirk E. Lifetime prediction for HALS-stabilized LDPE and PP. Polym Degrad Stab 1995;47(1):1-8. 